\title{
Immunohistological Reaction Mechanism of Anti-Monosialoganglioside Monoclonal Antibody, MAb 202, Showing Predominant Cytotoxicity for Malignant Melanoma
}

\author{
Takahisa Ota, Masahiko Muto, Junji Nakano, Sumiko \\ Hamanaka*, Reiko Irie $\dagger$ and Chidori Asagami \\ Department of Dermatology, Yamaguchi University School \\ of Medicine, Ube 755, *Department of Dermatology, \\ Yamaguchi Rousai Hospital, Onoda 765, and †Division of \\ Surgical Oncology, University of California Los Angeles, \\ School of Medicine, Los Angeles, CA 90024, USA
}

\begin{abstract}
Ota, T., Muto, M., Nakano, J., Hamanaka, S., Irie, R. and Asagami, C. Immunohistological Reaction Mechanism of Anti-Monosialoganglioside Monoclonal Antibody, MAb 202, Showing Predominant Cytotoxicity for Malignant Melanoma. Tohoku J. Exp. Med., 1995, 177 (1), 1-12— Mouse monoclonal IgM antibody (MAb 202) can cause melanoma cell necrosis in vivo. We analysed its immune mechanism in three melanoma patients to whom MAb 202 was administered. After the MAb 202 administration, histopathological analysis showed necrosis of melanoma cells expressing only GM3 in two patients. Another patient carrying both GM3 and GD3 showed infiltration of lymphocytes within the tumor nest but no tumor cells or nest necrosis. Immunohistological examination using anti-mouse IgM antibody revealed MAb 202 bound on the surface of melanoma cells in two patients but not in the third (positive for both GM3 and GD3). In vitro, MAb 202 reacted with the melanoma cells of the same two patients, but not with any other tissues of these individuals. We found no reaction of MAb 202 to non-melanoma cells including normal melanocytes and glia cells. Our trials suggest, 1) MAb 202 reacts directly to monosialogangliosides on the melanoma cell surface and then leads to the cytotoxicity reaction, or 2) MAb 202 induces lymphocyte infiltration and possibly then promotes the secretion of some cytokines. - melanoma; monoclonal antibody; MAb 202; ganglioside
\end{abstract}

Mouse monoclonal IgM antibody, MAb 202, recognizes specifically sialic acid $\alpha 2 \rightarrow 3$ galactosyl residues in monosialogangliosides and predominantly reacts with melanoma cells (Tai et al. 1987). We previously reported that a Japanese male patient with malignant melanoma, who was found to contain only GM3 within the

Received February 15, 1995; revision accepted for publication May 29, 1995.

Abbreviations: Abbreviations for gangliosides follow the Svennerholm nomenclature, L. Svennerholm, 1963; chromatographic separation of human brain gangliosides (J. Neurochem., 10, 613) 
tumor mass by an analysis of thin layer chromatography, showed necrosis of the melanoma cells by administration of MAb 202 (Hamanaka et al.1989). For further investigation of this cytotoxic effect by the MAb 202, we performed an immunohistological analysis of the reactions of MAb 202 against the only GM3carrying melanoma cells obtained from three different patients. Melanoma cells carrying both GM3 and GD3 and other non-malignant melanoma cells served as control samples. We show here that the reaction of MAb 202 against the melanoma cells might be a direct killing effect in case carrying only GM3, as compared with an indirect degenerative effect via possibly cytokines secreted from the infiltrating lymphocytes in case carrying both GM3 and GD3.

\section{Materials and Methods}

Preparation and nature of $M A b$ 202. MAb 202 was prepared from ascites of BALB/c mice and purified, as previously described by Katano et al. (1984). This mouse monoclonal IgM antibody recognizes sialic acid $\alpha 2 \rightarrow 3$ galactosyl residues in monosialoganglioside and reacts with human melanoma cells but not with normal cells (Tai et al. 1987). MAb 202 was made available to us by Dr. Tai (Tokyo Metropolitan Institute of Medical Science). MAb 202 was assayed for the absence of mouse viruses, bacteria and fungi.

Patients with malignant melanoma. Four Japanese patients with malignant melanoma were chosen; a 39-year-old man with metastatic subcutaneous nodules in the bilateral groin (Case 1), a 64-year-old man with a black tumor in the anorectal region and with metastatic subcutaneous nodules (Case 2), an 80-yearold woman with a black macule on the dorsum of the right foot (Case 3) and a 36-year-old woman with a black ovarian tumor (Case 4). One of them (Case 3) had a primary malignant melanoma without metastasis and the other three had metastatic malignant melanoma, stage IV. Two patients of cases 1 and 2 underwent anti-tumor therapies without showing any effectiveness. In Case 3, no chemotherapies were performed at the patient request.

Tissues for in vitro reactivity of MAb 202 containing monosialoganglioside. To examine the reactiveness of MAb 202 in vitro, 30 tissues derived from malignant melanoma, non-malignant melanoma, benign tumors and normal tissues of neural crest origin known to contain monosialogangliosides were collected. They were four malignant melanoma, one lentigo maligna, three neurofibroma, two schwannoma, ten nevus cell nevus, three Spitz nevus, two nevus spilus, two normal human brain (glia cell) and three normal human skin (melanocytes). The final diagnosis was made by histopathological analysis in all cases. Tissue samples were snap-frozen in liquid nitrogen and stored at $-80^{\circ} \mathrm{C}$ until used.

Ganglioside analysis of malignant melanoma cells. Gangliosides extracted from the tissues of each patient with 20 volumes of chloroform-methanol (2:1,1: $1,1: 2$, by volume) were purified by the methods of Ledeen et al. (1973). They were analyzed on thin-layer chromatography (TLC) developed with chloroform- 
methanol-0.02\% $\mathrm{CaCl}_{2}$ solution (55:45:10, by volume) and chloroformmethanol-2.5N ammonium solution $(60: 40: 9$, by volume). Then the gangliosides were visualized by spraying resorcinol reagent (Tsuchida et al. 1987), and heated at $95^{\circ} \mathrm{C}$ for $30 \mathrm{~min}$ with the glass cover on the plate.

Administration of MAb 202. The MAb 202 was assayed for mouse viruses, bacteria and fungi and no pathogens were detected. The clinical trials were conducted with the written consent of patients. In Case 1, 50 $\mu \mathrm{g}$ of MAb 202 was administered intralesionally into an $11 \times 11 \mathrm{~mm}$ tumor of the groin every three days for three treatments (total $150 \mu \mathrm{g}$ ). In Case 2, $500 \mu \mathrm{g}$ of MAb 202 was administered intralesionally into a $10 \times 10 \mathrm{~mm}$ tumor on the breast five times every other days (total 2,500 $\mu \mathrm{g}$ ). In Case 3, $50 \mu \mathrm{g}$ of MAb 202 was administered subcutaneously into the primary tumor every other day for five treatments (total $250 \mu \mathrm{g}$ ). As a control, $1 \mathrm{ml}$ of saline was administered to other lesions on each patient under the same regimes. Case 4 was not treated with MAb 202. In Cases 1,2 and 3, two days after the final administration, each tumor injected with MAb 202 was resected and submitted for histopathological and immunohistological examinations.

Immunohistological technique. Tissue sections were processed for immunohistochemical reactions using a three-stage streptavidin-biotin-coupled peroxidase method. The specimens injected with MAb 202 and saline were embedded in paraffin after fixation with buffered $10 \%$ formaline, and cut into $4 \mu \mathrm{m}$-thick sections. They were deparaffinized and dehydrated by routine procedures. The biotin-streptavidin kit was perchased from BioGenex Lab (Dublin, CA, USA). To detect surface markers for mononuclear infiltrates, formaline-fixed sections of $4 \mu \mathrm{m}$ in thickness were incubated with the diluted antibodies for $30 \mathrm{~min}$ at room temperature. The antibodies used were UCHL-1 (anti-CD45RO; Dako, Denmark), L26 (anti-CD20; Dako) and KP-1 (anti-CD68; Dako). These monoclonal antibodies are all IgG. After that they were incubated for $30 \mathrm{~min}$ at room temperature in biotinylated rabbit anti-mouse IgG (Dako). Finally, incubation was carried out to form streptavidin-biotin-peroxidase complexes for $30 \mathrm{~min}$ at room temperature. Sections were then immersed in diaminobenzidine for visualization.

Regarding immunoreactivity of MAb 202 with tissue sections, $50 \mu \mathrm{g} / \mathrm{ml}$ of MAb 202 were pre-incubated with the tissue sections, after washing twice with phosphate-buffered saline, for $2 \mathrm{hr}$ at $37^{\circ} \mathrm{C}$. Then the sections were washed again and incubated with rabbit anti-mouse IgM antibodies (Dako) for $30 \mathrm{~min}$ at $37^{\circ} \mathrm{C}$. Subsequent procedures for immunostaining are the same as the method used to detect surface markers for mononuclear infiltrates within the tumor. Biotinylated goat anti-rabbit immunoglobulin was used as linking antibody (BioGenex Lab).

Counterstaining was carried out with the omission of the primary antibody and uses as a negative control. To distinguish positive findings from melanin, 
Giemsa's staining was performed before coverslipping. Melanin granules were stained deep green, in contrast to the monosialogangliosides which were positively stained brown.

\section{Results}

\section{Ganglioside analysis}

As shown in Fig. 1, GM3 was the only ganglioside detected on TLC in the tumors from Cases 1 and 2. However, GM3 and GD3 were detected in the tumors from Cases 3 and 4 (Fig. 1).

Clinical and histopathological findings. As shown in Table 1, clinical and laboratory findings are summarized. After the injection of MAb 202, the size of the lesions reduced from $11 \mathrm{~mm}$ to $9 \mathrm{~mm}$ in diameter with some redness at the injection site in Case 1, and from $10 \mathrm{~mm}$ in diameter to $8 \times 9 \mathrm{~mm}$ in Case 2 . In Case 3 , the size of the tumor did not clinically change and a bulla formed at the injection site two days after the fifth and final injection. No side effects of anaphylactic shock were observed except for the local redness in Case 1 and the bulla formation in Case 3. There was no change at any of the saline injection sites used as controls.

The histological examination revealed a decrease of spindle-shaped melanoma cells and replacement by fibrosis in Case 1 (Figs. 2a, b). This indicates partial necrosis of the tumor cells. Lymphocytes and plasma cells had infiltrated around the tumor mass. In Case 2, tumor cell necrosis was observed in the center of the tumor mass with neutrophils, lymphocytes and macrophages around it (Figs. 3a, b). In Case 3, the lesion showed the following features; 1) the nest of melanoma cells completely disappeared and the tumor cells were sparcely present, 2) melanoma cells in the dermis showed vacuolating degeneration, 3) infiltrated lymphocytes showed a follicular pattern in more degenerated lesions and a diffuse

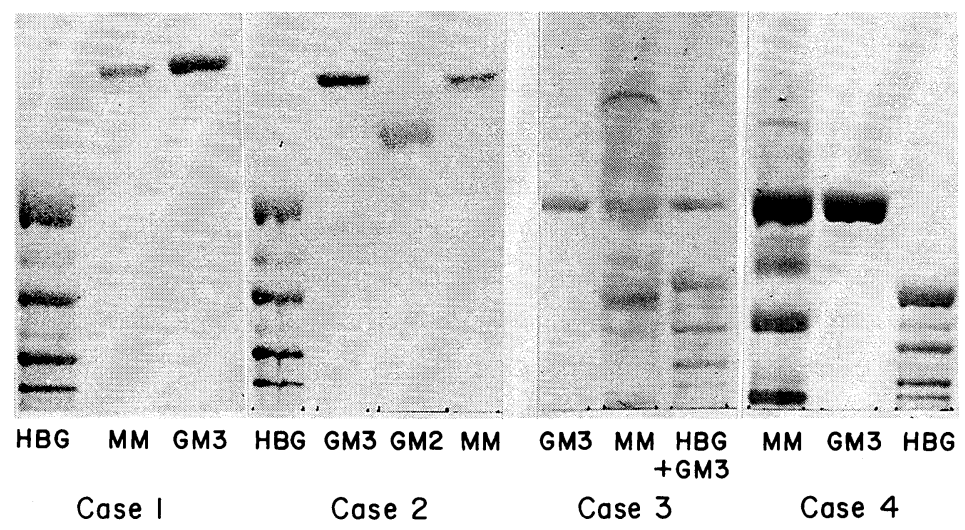

Fig. 1. Ganglioside analysis of melanoma cells used in the present study. $\mathrm{HBG}$, human brain ganglioside; MM, ganglioside from melanoma. 


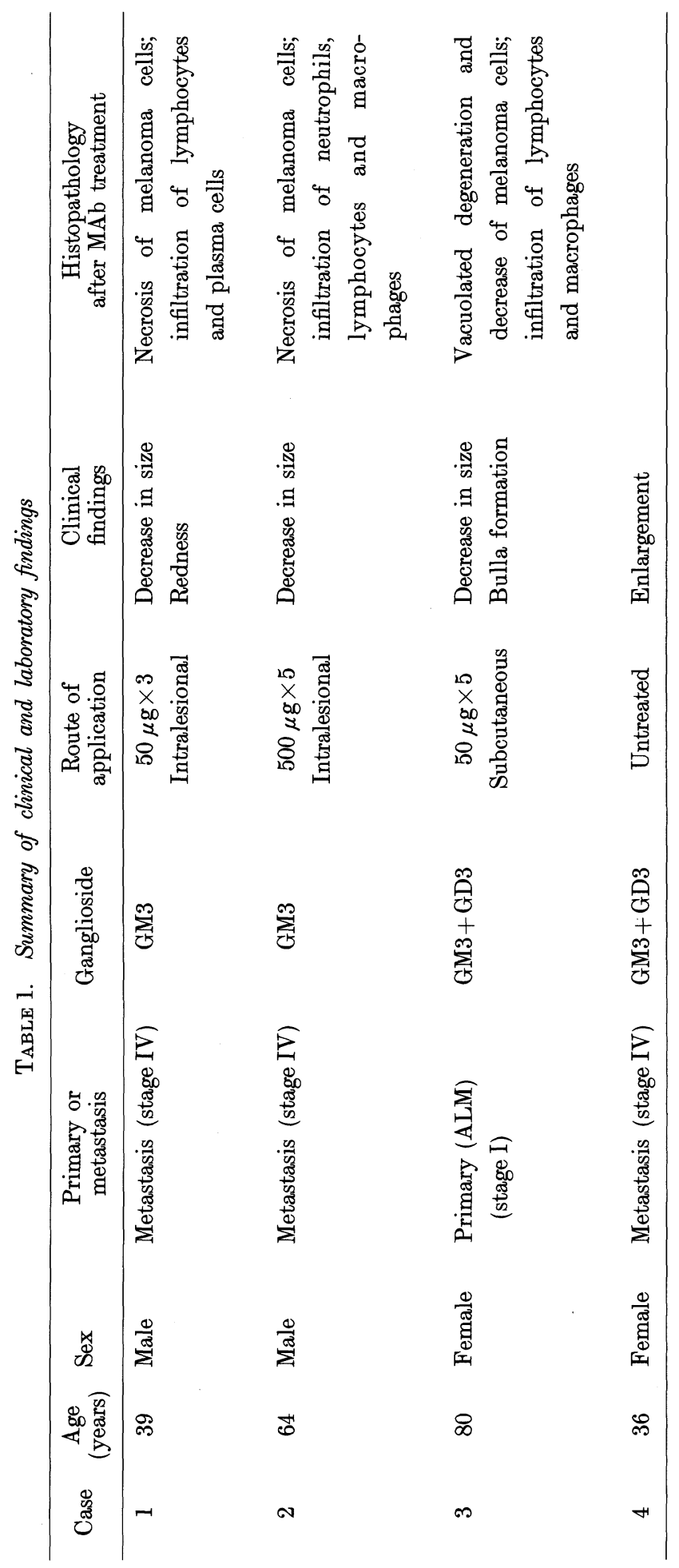




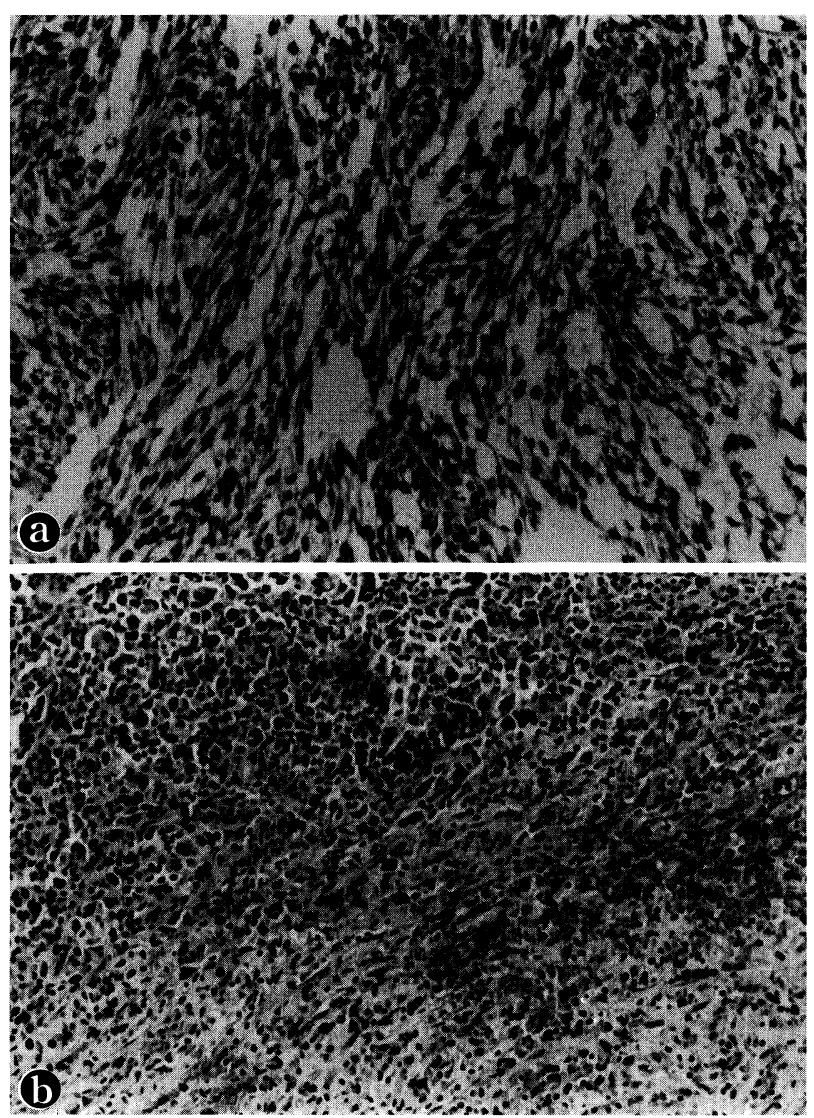

Fig. 2. Histopathological findings of before (a) and after (b) MAb 202 treatment in Case 1. Note a decrease of spindle-shaped melanoma cells and replacement by fibrosis after treatment. (H.E. $\times 100)$

pattern in less degenerated lesions, 4) melanophages appeared in the upper to middle dermis, and 5) melanins removed transepidermally (Figs. 4a, b, c). At the central lesions injected with saline, no histopathological changes were observed except for mild dermal infiltration of mononuclear cells within the dermis in Case 3 (Fig. 5).

Analysis of surface markers of the infiltrates. We performed immunostaining of the tissue of both MAb 202-injected and saline-injected sites concerning Case 3. The data are summarized in Table 2. In the follicular-patterned lesions of the mononuclear cells, both $\mathrm{T}$ and $\mathrm{B}$ cells were densely observed, whereas macrophages were few (Figs. 6a, b, c). However, in the diffuse-patterned lesions, $\mathrm{T}$ cells were only predominant (Figs. $6 \mathrm{~d}, \mathrm{e}, \mathrm{f}$ ). At the site administrated saline, many of the infiltrates were $\mathrm{T}$ cells.

Immunohistological findings. Each of the specimens taken from the tumors of Cases 1 and 2, after MAb 202 treatment, stained positive for MAb 202 along the 


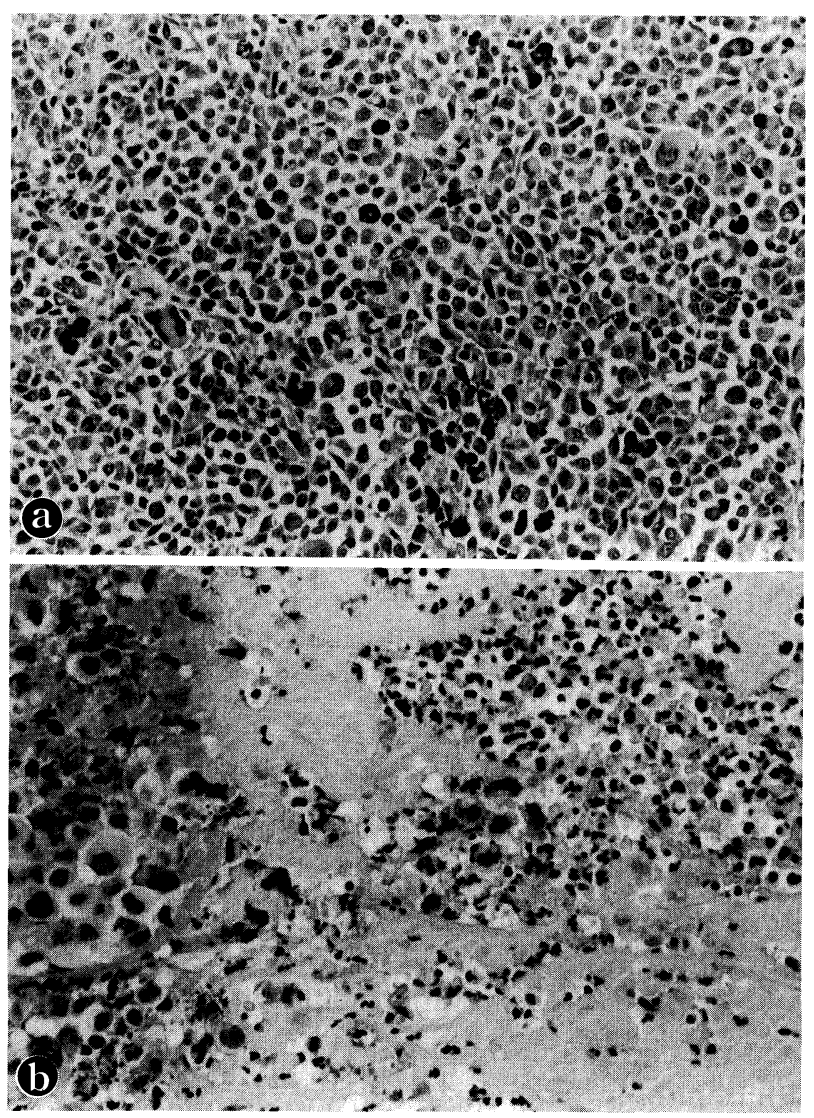

Fig. 3. Histopathological findings of before (a) and after (b) MAb 202 treatment in Case 2. Tumor cell necrosis was observed in the center of the tumor mass with infiltration of neutrophils, lymphocytes and macrophages around the necrotic tumor mass. (H.E. $\times 100)$

TABLE 2. Immunohistochemical analysis of infiltrating mononuclear cells

\begin{tabular}{ccccccccc}
\hline & \multicolumn{3}{c}{ Diffuse-patterned lesion } & & \multicolumn{3}{c}{ Follicular-patterned lesion } \\
\cline { 2 - 3 } & T cell & B cell & M $\phi^{*}$ & & T cell & B cell & M $\phi^{*}$ \\
\hline $\begin{array}{c}\text { Site administrated } \\
\text { MAb 202 }\end{array}$ & $\#$ & \pm & \pm & & $\#$ & $\#$ & \pm \\
$\begin{array}{c}\text { Site administrated } \\
\text { saline as control }\end{array}$ & + & \pm & & & & not observed & \\
\hline
\end{tabular}

${ }^{*} \mathrm{M} \phi$, Macrophage. 

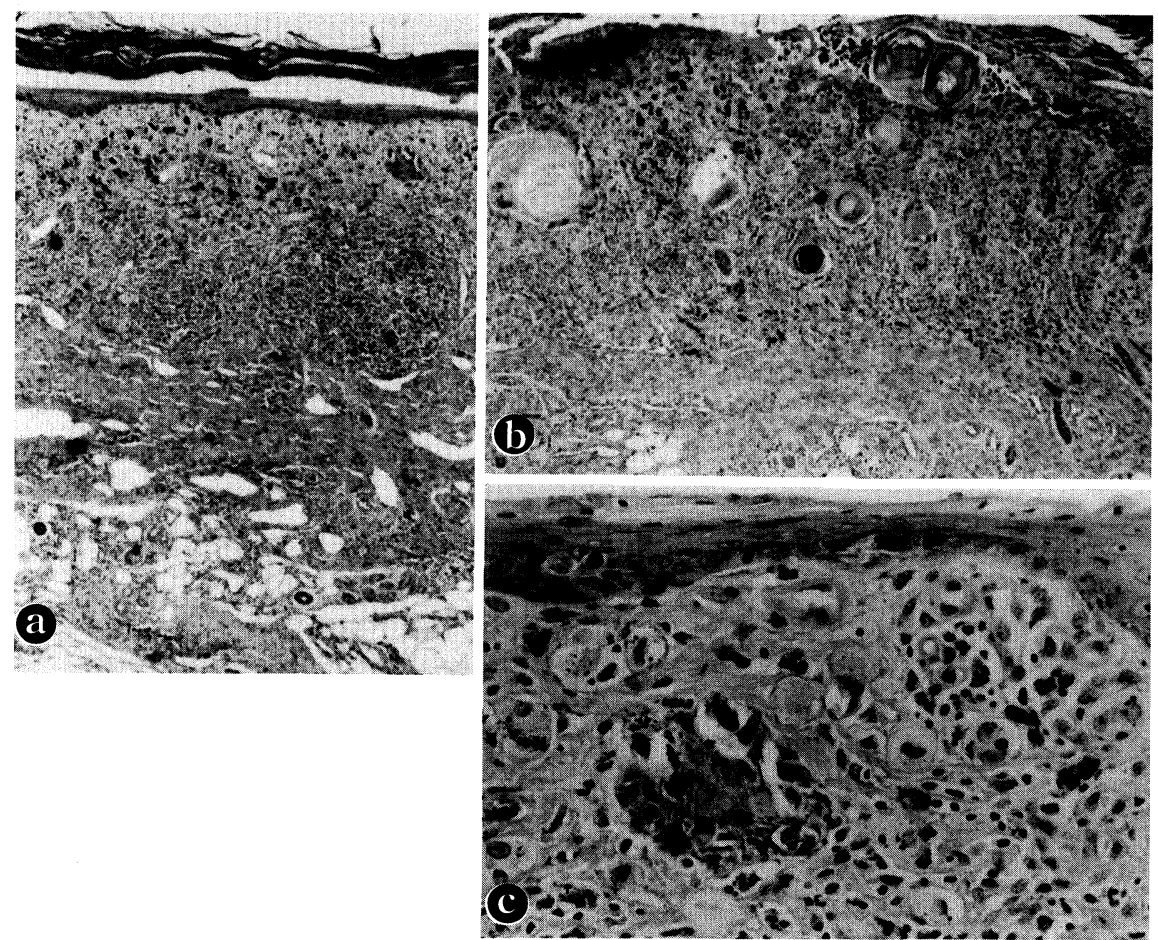

Fig. 4. Histopathological findings of after treatment with MAb 202. Lymphocytes were infiltrated showing a follicular pattern in more degenerated lesions (a) and a diffuse pattern in less degenerated lesions (b). Melanoma cells in the dermis showed vacuolating degeneration (c). (H.E. $\times 100,400)$

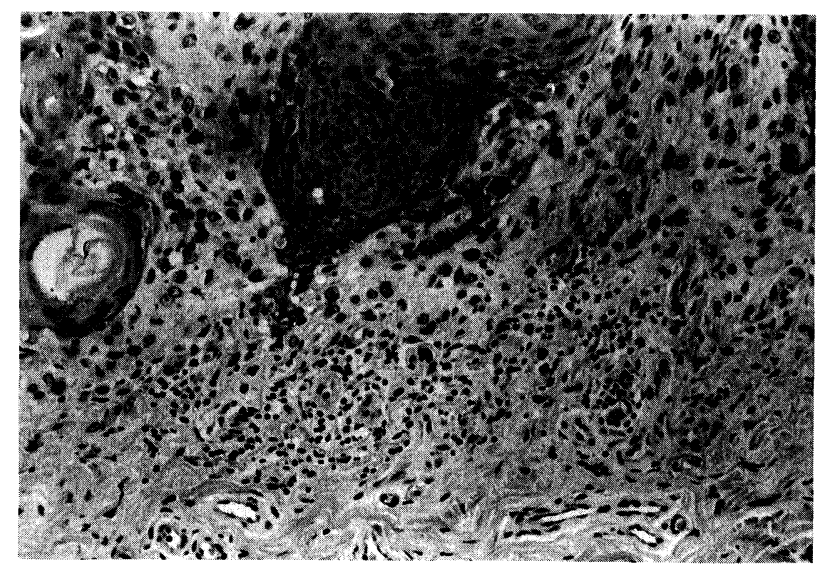

Fig. 5. Histopathology of site administrated saline. There was only mild infiltration of lymphocytes. (H.E. $\times 100)$ 

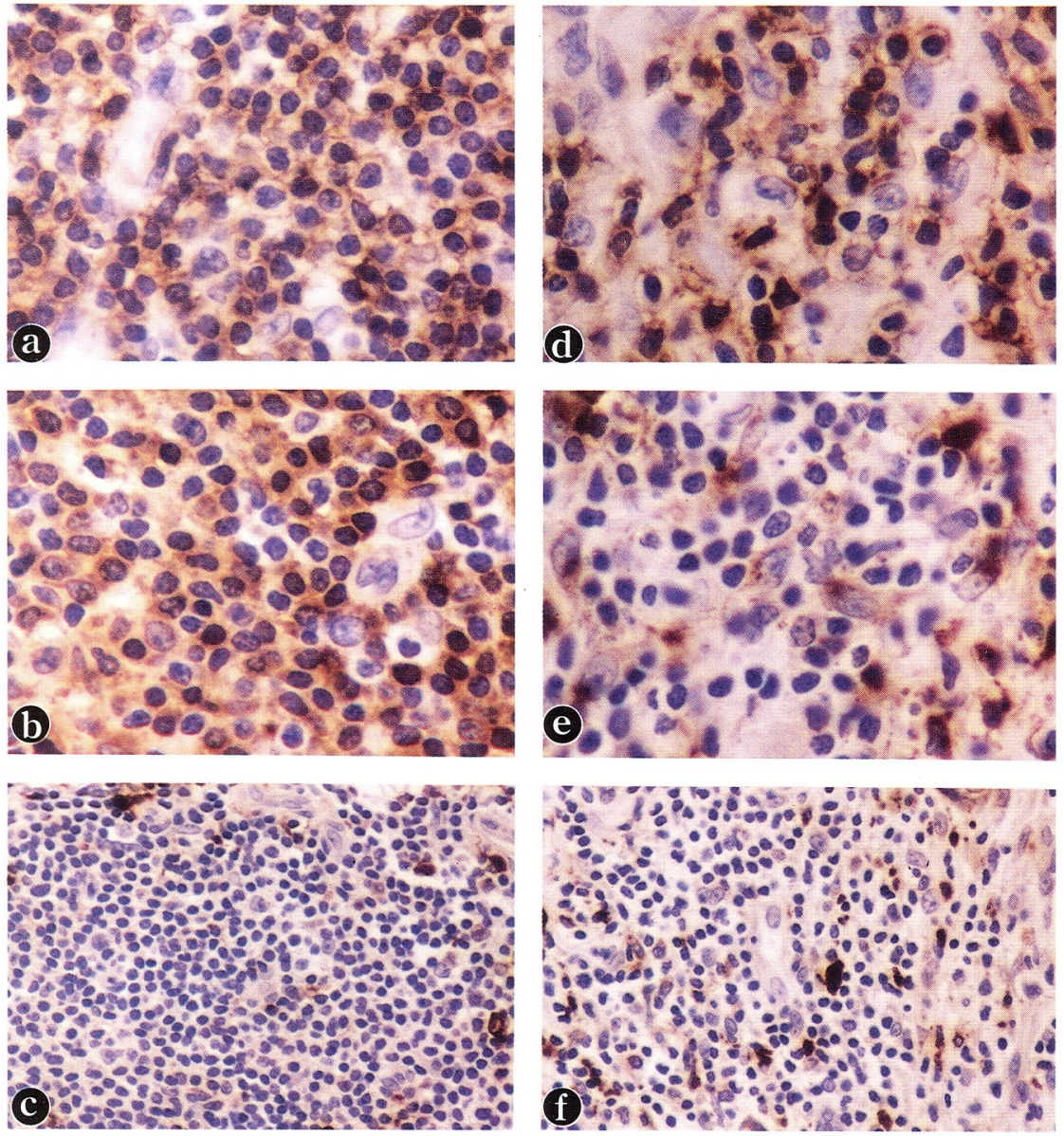

Fig. 6. Immunohistochemical analysis of the infiltrates. (Left) Follicular-patterned lesions.
(a) UCHL-1-positive cells,
(b) L26-positive cells,
(c) KP-1-positive cells.
(Right) Diffuse-patterned lesions.
(d) UCHL-1-positive cells, (e) L26-positive cells, (f) KP-1-positive cells.
$(\times 200,100)$

surface of melanoma cells. The cytoplasms of melanoma cells, lymphocytes and vessel walls did not stain positively (Figs. 7a, b; Case 1). The specimens from Case 3 (after MAb 202 treatment) and those from Case 4 (untreated) were negative. None of the 26 tissues of neural crest origin stained positive for MAb 202 (Table 3).

\section{Discussion}

The present immunohistopathological study of MAb 202 against melanoma cells indicates evidence for two distinct mechanisms of either indirect or direct anti-tumor effects. In all cases of Cases 1,2, and 3, immune cells were observed. 


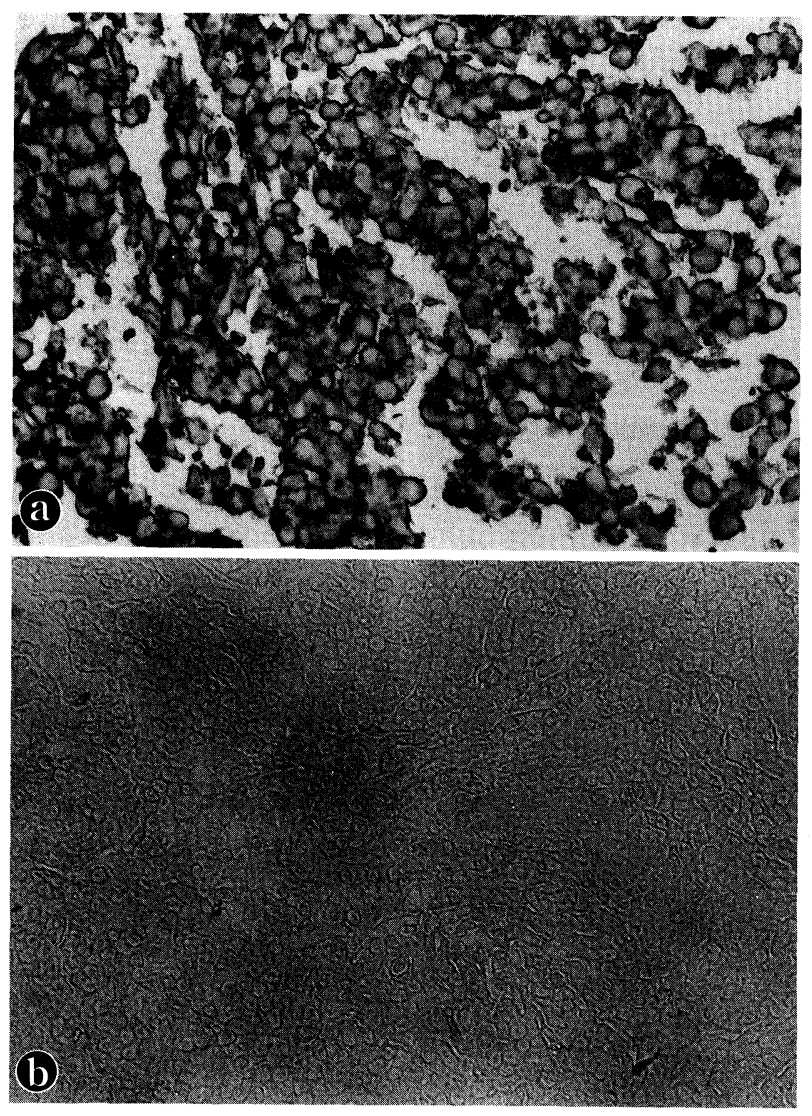

Fig. 7. Tissue reactions to MAb 202 after treatment. Surfaces of melanoma cells were positive for MAb 202 (a), whereas the cytoplasms of the tumor cells, lymphocytes and vessel walls were negative (b). $(\times 200)$

TABLE 3. Reactiveness of MAb 202

\begin{tabular}{lcc}
\hline & $\mathrm{P} / \mathrm{E}^{*}$ & Positivity \\
\hline Malignant melanoma & $2 / 4$ & $50 \%$ \\
Lentigo maligna & $0 / 1$ & $0 \%$ \\
Neurofibroma & $0 / 3$ & $0 \%$ \\
Schwannoma & $0 / 2$ & $0 \%$ \\
Nevus cell nevus & $0 / 10$ & $0 \%$ \\
Spitz nevus & $0 / 3$ & $0 \%$ \\
Nevus spilus & $0 / 2$ & $0 \%$ \\
Normal brain & $0 / 2$ & $0 \%$ \\
Normal skin (melanocyte) & $0 / 3$ & $0 \%$ \\
Total & $2 / 30$ & \\
\hline
\end{tabular}

${ }^{*} \mathrm{P} / \mathrm{E}$, Positive/Examined. 
The infiltrates were composed of lymphocytes (all Cases), plasma cells (Case 1), neutrophils (Case 2) and macrophages (Cases 2,3). This result suggests that at various stages, chemokines released from the melanoma cells by interaction between MAb 202 and GM3 might attract immune cells which could damage the melanoma cells. To clarify this possibility, it is informative to investigate interaction between MAb 202 and GM3 by using cultured melanoma cells positive for GM3.

In addition to the above indirect anti-tumor effect, the MAb 202 had a strong direct killing effect against melanoma cells, as shown in Cases 1 and 2. Using electron microscopy, Asagami et al. (1989) observed indented nuclei, giant nuclear pockets, vacuolated mitochondria and melanosomes within the melanoma cells and suggested that MAb 202 might react not only on the tumor cell membrane but also on the nuclear membrane and on cytoplasmic organella. In contrast, melanophages, lymphocytes and endothelial cells were intact. This fact also supports that MAb 202 damgaged the melanoma cells directly. We previously reported that MAb 202 had antitumor effects against melanoma cells via complement-dependent cytotoxicity but not antibody-dependent cellular cytotoxicity (Hamanaka et al. 1989). Therefore it is feasible that cellular mechanism of necrosis of the melanoma cells seen in the Cases 1 and 2 was based on a fashion of the complement-dependent cytotoxicity. Differences of dose administered of MAb $202(50 \mu \mathrm{g} \times 3$ in Case 1 and $500 \mu \mathrm{g} \times 5$ in Case 2) could have an effect for kinds of immune cells infiltrating into or around the melanoma cells. In Case 3 (GM3 and GD3 both positive), the lack of immunostaining with the MAb 202 might be due to decreased amount of GM3 expressed on the surface of melanoma cells, as compared with the melanoma cells which were positive for only GM3. Lloyd et al. (1992) indicated that accessibility of individual gangliosides in malignant melanoma cells to antibodies is influenced by the total ganglioside composition of the cells. Another possibility was the limited sensitivity of immunostaining methods used in the present study. To improve this problem, it is necessary to use a more sensitive technique like the immuno-adherence assay (Tai et al. 1987). The reactivity of MAb 202 for the monosialoganglioside might be also affected by other components such as protein and glycoprotein (Hakomori and Kannagi 1983).

MAb 202 reacted to melanoma cells, whereas there was no reaction to benign tumor (non-melanoma). cells of neural crest origin, SCC, BCC and normal skin, despite their containing large numbers of monosialogangliosides. Therefore, specificity of MAb 202 for melanoma cells was reconfirmed.

In conclusion, mouse monoclonal IgM antibody (MAb 202) could cause necrosis or degeneration of the melanoma cells in vivo. Its immune mechanisms involved both cytokine-induced degeneration and direct cytotoxicity by MAb 202. 


\section{Acknowledgment}

We wish to thank Dr. T. Tai and Dr. I. Kawashima (Tokyo Metropolitan Institute of Medical Science) for providing MAb 202, Drs. K. Nishioka and T. Imamura for supports in this research, and Mrs. R. Suzuki for her help. We also thank Dr. H. Saito (Nagasaki University School of Medicine) for virus assays.

\section{References}

1) Asagami, C., Ota, T., Ogasawara, M., Nakano, J., Imamura, T., Hamanaka, S., Tai, T. \& Irie, R. (1989) Ultrastructural study for the mechanism of cytotoxic effect against cutaneous metastatic malignant melanoma by intralesional injections with antimonosialoganglioside mouse monoclonal antibody (MAb 202). J. Clin. Electron. Microscopy, 22, 922-923.

2) Hakomori, S. \& Kannagi, R. (1983) Glycosphingolipids as tumor-associated and differentiation marker. J. Natl. Cancer Inst., 71, 231-251.

3) Hamanaka, S., Ota, T., Nakayasu, K., Kamei, T., Tai, T., Kawashima, I., Otsuka, F., Irie, R. \& Asagami, C. (1989) Strong anti-tumor effect of monosialo-ganglioside specific monoclonal antibody 202: A clinical trial in cancer patient with melanoma. J. Dermatol., 16, 480-486.

4) Katano, M., Saxton, R.E. \& Irie, R.F. (1984) Human monoclonal antibody to tumor-associated ganglioside GD2. J. Clin. Lab. Immunol., 15, 119-126.

5) Ledeen, R.W., Yu, R.K. \& Eng, R.F. (1973) Gangliosides of human myelin: Sialosylgalactosylceramide (G7) as a major component. J. Neurochem., 21, 829-839.

6) Lloyd, K.O., Gordon, C.M., Thampoe, I.J. \& DiBenedetto, C. (1992) Cell surface acessibility of individual gangliosides in malignant melanoma cells to antibodies is influenced by the total ganglioside composition of the cells. Cancer Res., 52, 49484953.

7) Tai, T., Sze, L., Kawashima, I., Saxon, R.E. \& Irie, R.F. (1987) Monoclonal antibody detects monosialogangliosides having a sialic acid $\alpha 2 \rightarrow 3$ galactosyl residue. J. Biol. Chem., 262, 6803-6807.

8) Tsuchida, T., Saxton, R.E., Morton, D.L. \& Irie, R.F. (1987) Gangliosides of human melanoma. J. Natl. Cancer Inst., 78, 45-54. 